\title{
Observations and Modelling of Compressive Failures of Hard Rock Masses
}

\author{
C. Edelbro Luleå University of Technology, Sweden
}

\begin{abstract}
Observations from five case studies of induced compressive brittle failure fallouts are compared with different numerical modelling approaches, to determine the best non-calibrated approach. All case studies are situated in hard rock masses that are massive or sparsely fractured, at depths of 630-965 $\mathrm{m}$ below surface. The observed fallouts are compared with the results from numerical models in Examine2D and Phase2D. The objective is to identify which of the five numerical modelling approaches gives the best agreement with respect to location, depth, shape, and extent of the observed fallouts. None of the studied approaches give perfect agreement with the actual fallouts. This study demonstrates that when rock mass strength parameters are defined by either the Hoek-Brown or the Mohr-Coulomb criterion, the elastic and elastic-perfectly plastic models predict reasonably well actual fallout depth, although the extent of fallout is exaggerated and the shape incorrect. Therefore, a precise estimation can not be expected. When using the $m=0$ approach, the results were in poor agreement with the observed fallout. The fallouts are significantly overestimated when applying the brittle-plastic model using instantaneous softening by cohesion and friction or cohesion weakening.
\end{abstract}

\section{Introduction}

Increases in mining depths lead to higher stresses and thus an increased risk of instability. The prediction of failure due to high compressive stresses around deep underground openings is thereby of great importance. Different kinds of methods, such as failure criteria, numerical models and analytical models have been developed to predict rock mass failure with different degrees of success, primarily due to the difficulty in reproducing the field-scale behaviour and failure mechanisms of rock masses.

The objective of this paper is to run field data, without modification, for a number of case studies in different numerical models to find the best non-calibrated approach. The purpose of the comparison is to identify which frequently used approach gives the best agreement with the observed fallouts with respect to location, depth, shape, and extent. Observed fallouts are compared with the predicted fallouts from numerical models in the stress analysis programs Examine2D (Rocscience Inc., 2007) and Phase2D (Rocscience Inc., 2005). These programs selected used as they are easy to use and widely available within the mining and geoengineering fields. For elastic analysis, the stability of the excavation was evaluated through the Strength Factor (SF), thus assuming that a region will fall out if $\mathrm{SF}<1$. For plastic analysis, the failed region can be identified by yielded elements.

The five cases presented here comprise, two road tunnels in Norway, two vertical raises in the Garpenberg mine, and an exploration drift in the Zinkgruvan mine (both mines located in Sweden). Detailed descriptions of the fallouts, geology and stress data are presented for each case.

\section{Strength and modelling of brittle hard rock masses at depth}

Failure can occur during all phases of the life of a construction, from excavation to utilisation. Different stages can be identified in the failure process, see Figure 1. The first indication that the rock mass strength has been exceeded is by visible cracks on the boundary of the excavation. In mines, the stress field changes in response to mining extraction. Increases in stress at this point lead to crack accumulation and growth. Further increases in stress result in joint interaction, causing fallouts to occur. For constructions in a constant stress field, such as tunnels, one, two or all of the stages in Figure 1 may develop. If the joints do not interact, the boundary is "only" damaged. All of these stages, from damage initiation to fallout are often collectively referred to as failure. In this paper, only the final stage, i.e. fallouts in hard rock masses, is being studied as 
this state constitutes the actual problem for the utilisation of an underground opening. Also the first documented observation is often when a fallout occurs as the first stages either occur directly prior to fallout, are difficult to observe or are not perceived to be of enough interest to affect stability.

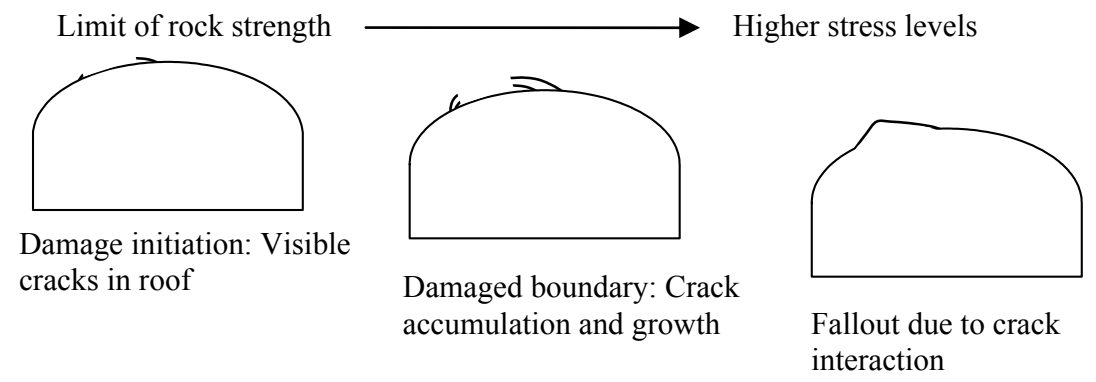

Figure 1 Schematic picture of different stages of the failure process

Rock stresses can be measured, albeit indirectly through e.g. measurements of strain for a stress-relieved rock volume, or normal stress on a pressurised fracture. Also, the strength of intact rock and the shear strength of joints can be measured through standardised laboratory testing. However, the strength of a rock mass is difficult to measure as the scale for a typical design situation underground precludes physical testing, other than in very special, and isolated, circumstances. Moreover, the interaction between the intact rock and the discontinuities within the rock mass is often complex, and less well understood (compared to the behaviour of the individual units), thus making it difficult to predict the rock mass strength solely from strength data on intact rock and small-scale discontinuities. Back-analysis of fallouts is perhaps the most accurate method for rock mass strength determination, however, it requires data of the fallout, a reasonable failure model, and similar rock conditions for forward prediction. There has been little work in the literature that deals with field scale behaviour and described fallouts of the rock. One case that has been used to calibrate numerical models for brittle failure is the Underground Research Laboratory (URL) in Canada that is situated in non-fractured massive granite (e.g. Martin, 1997, Diederichs, 1999, Hajiabdolmajid et al., 2002). It is necessary to analyse a larger number of case histories concerning fallouts to increase the understanding of the fallout characteristics and the failure process.

The most widely referred and used criteria for rock mass strength determination, are the Hoek-Brown and Mohr-Coulomb failure criteria. The probable reasons why the Mohr-Coulomb linear criterion is so commonly used in geotechnical engineering is that it is described by a simple mathematical expression, is easily understood and simple to use. The Mohr-Coulomb criterion can be expressed, based on triaxial data and in principal stresses, as

$$
\sigma_{1}=\frac{2 c \cos \phi}{1-\sin \phi}+\sigma_{3} \frac{1+\sin \phi}{1-\sin \phi}
$$

where $\mathrm{c}$ is the cohesion and $\phi$ the friction angle. The generalised non-linear definition of the Hoek-Brown criterion (Hoek et al., 2002) is described by

$$
\sigma_{1}=\sigma_{3}+\sigma_{c i}\left(m_{b} \frac{\sigma_{3}}{\sigma_{c i}}+s\right)^{a}
$$

where $\sigma_{1}$ and $\sigma_{3}$ are used instead of $\sigma_{1}{ }^{\prime}$ and $\sigma_{3}{ }^{\prime}$ as no water pressure is considered. The $s, m_{b}$ and $a$ are constants which depends upon the rock mass characteristics and are defined as

$$
\begin{array}{r}
m_{b}=m_{i} \exp \left(\frac{G S I-100}{28-14 D}\right) \\
s=\exp \left(\frac{G S I-100}{9-3 D}\right)
\end{array}
$$




$$
a=\frac{1}{2}+\frac{1}{6}\left(e^{-G S I / 15}-e^{-20 / 3}\right)
$$

where $\mathrm{D}$ is a factor that depends on the degree of disturbance, $\mathrm{m}_{\mathrm{i}}$ is a constant for the intact rock and GSI is the geological strength index. When determining the intact rock strength, mi is used instead of $m_{b}$ and $\mathrm{s}=1$ and $a=0.5$. The rock mass jointing is described by rock structure and joint surface condition in the GSI system. For massive rock masses the GSI value is generally very high (often $>70$ ) and $m_{b}, s$ and $a$ approaches the intact rock values. As pointed out by Marinos et al. (2005) the application of the GSI system is no longer regarded as meaningful in hard rock at great depths with tight interlocks. Regardless, the back calculated strength for fallout in massive brittle rock is often significantly lower than $50 \%$ of the laboratory strength of the intact rock (e.g. Myrvang, 1991, Diederichs et al., 2004).

As suggested by Hoek et al. (1995), an elastic-brittle material model, with low residual values of cohesion and friction angle, should be best suited to represent brittle failure. In 1990 at URL in Canada, research on the observed brittle failure, was performed using back-analysis and numerical modelling. It was observed that failure occurs in the region of maximum tangential stress around the boundary and that stress-induced fracturing around the tunnel initiated at approximately $0.3-0.5$ the intact uniaxial compressive strength $\left(\sigma_{\mathrm{c}}\right)$ (e.g. Martin et al., 1997, Diederichs et al., 2007). The typical V-shaped notches caused by the fallouts were reported (Martin et al., 1997) and different proposed methods on modelling brittle rock failure (e.g. Martin, 1998, Hajiabdolmajid et al., 2002). As the proposed methods to model brittle failure of rock have been developed for one certain geological environment, these are assumed applicable for similar rock conditions elsewhere. Some of the models were calibrated so that the results, in terms of strength factor and yielded elements, would suit the depth, extent and shape of the failures which is defined in this paper as equivalent to fallout. The application of the strength parameters in Hoek-Brown criterion (Martin et al., 1999) resulted in a suggestion that the location and depth of failure (but not the shape and extent) could be well estimated when using a values of $m_{b}$ close or equal to zero and $\mathrm{s}=0.112$ in an elastic analysis (which represents failure initiation at $0.3 \cdot \sigma_{\mathrm{c}}$ ). Similar findings of low confinement dependency were presented by Diederichs et al. (2004), who summarised research of back-analyses of brittle failure on damage initiation.

To determine whether it is meaningful to use GSI system with values $>70$, when simulating a fallout in a brittle hard rock mass, both an approach where the strength parameters are defined by the intact rock and one where the GSI system was used, to estimate the "down-scaled" rock mass strength (outlined in Sections 3.2.1 and 3.2.2). In addition, three different elastic-brittle plastic material approaches were used:

- $m=0,($ Section 3.2.3).

- A cohesion and friction instantaneous softening approach as suggested by Hoek et al. (1995) (Section 3.2.4).

- A cohesion instantaneous softening approach (Section 3.2.5).

\section{Numerical modelling of fallouts}

\subsection{Numerical codes}

The observed/actual fallout were compared with the results from numerical models in the stress analysis programs Examine ${ }^{2 \mathrm{D}}$ (Rocscience Inc., 2007) and Phase ${ }^{2 \mathrm{D}}$ (Rocscience Inc., 2005). Phase ${ }^{2 \mathrm{D}}$ is an elastoplastic finite element stress analysis program, in which the material can yield and exhibit non-linear stressstrain behaviour if treated as plastic. If the peak strength is exceeded, residual strength values can be applied by treating the material as either elastic-perfectly plastic or as elastic-brittle plastic (Figure 2). Examine ${ }^{2 \mathrm{D}}$ is an indirect boundary element program, which models the rock as a linear elastic material. Both of these programs are used for calculation of stresses and displacements around underground and surface excavations in rock. Since the material cannot yield in Examine ${ }^{2 \mathrm{D}}$, this program has been used only to verify and compare the results from the Phase ${ }^{2 \mathrm{D}}$ elastic analysis. For elastic analysis, the stability of the excavation is evaluated through the Strength Factor (SF), assuming fallout occurs if $\mathrm{SF}<1$. In the plastic analysis, the fallout can be identified by yielded elements near the boundary of excavation. 


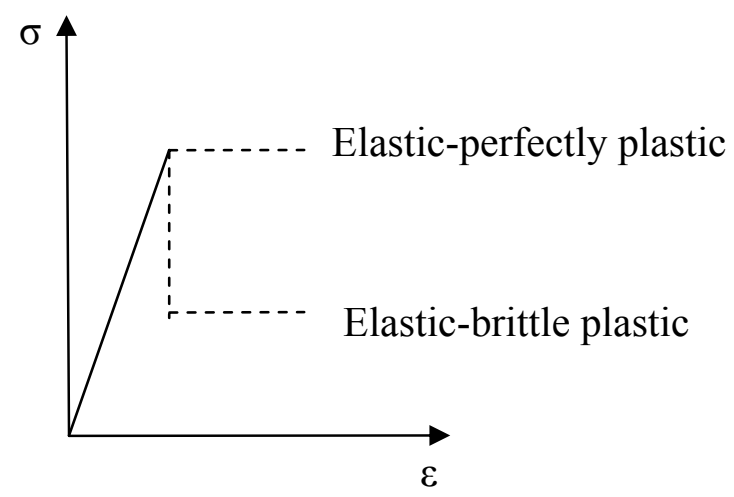

Figure 2 Schematic picture of material models used in Phase ${ }^{2 D}$

Based on the URL case, it has been shown that outside the notch region, e.g. outside the fallout, the rock mass is more or less undamaged (Hajiabdolmajid et al., 2002). Therefore in this paper, it is assumed that an area of $100 \%$ yielded elements or SF less than one represents fallout.

\subsection{Methodology}

For each case, rock stress measurements, rock mass characterisation and laboratory testing have been carried out and used to identify the stress conditions, the geological strength index, GSI (Hoek and Karzulovic, 2001), the uniaxial compressive strength, Young's modulus and Poisson's ratio of the intact rock. The peak strength parameters of the rock mass are based on the generalised Hoek-Brown (Hoek et al., 2002) criterion and equivalent Mohr-Coulomb parameters. To get input data, in terms of cohesion $(c)$ and friction angle (ø), a Mohr-Coulomb failure envelope has been matched to the Hoek-Brown failure envelope using the program RocLab, (RocScience, 2006). This linear regression is made for a minor principal stress range of $\sigma_{t m}$ through $\sigma_{3 \max }$, where $\sigma_{\mathrm{tm}}$ is the tensile strength of the rock mass and $\sigma_{3 \max }$ is the upper limit of confining stress over which the relationship between the Hoek-Brown and the Mohr-Coulomb criteria is considered. The value of $\sigma_{3 \max }$ was selected as the $\sigma_{3}$ value at a distance of one tunnel width beyond the boundary based on an elastic analysis. The dilation angle was set to zero in all models as all cases can be considered as constrained. This is considered conservative as a higher dilation angle should produce a higher failure load. The disturbance factor, D, is set to zero for all cases as controlled blasting or raising has been used.

Three different material models have been used: (i) elastic, (ii) elastic-perfectly plastic, and (iii) elasticbrittle plastic. One of the simplest ways of estimating the depth, shape and extent of the fallout is by the use of an elastic model. However, an elastic model cannot "fail", so a strength factor value less then one is considered to represent failure within the material. In an elastic-perfectly plastic model a material weakening is not simulated but includes the effect of plastic straining. The failure process in elastic-brittle plastic models is simulated by instantaneous softening of the rock mass strength parameters.

The evaluation of each case study and approach used was carried out by:

- Defining the input data from field studies and/or documented information of the cases.

- Run an elastic model, based on the defined input data, to determine the $\sigma_{3 \max }$-value.

- Use selected approaches and criteria, in Table 1 and Sections 3.2.1 through 3.2.5, to determine stresses, strains, strength factors and yielded elements.

- Evaluate the outcome and compare the simulated fallout zone with the observed fallout. The predicted fallout depth, extent and shape is determined by adding an iso-line with a constant value of $\mathrm{SF}=1$ and $100 \%$ yielded elements for the elastic and plastic analyses, respectively. 
Table 1 Applied criteria to determine the strength parameters in the used approaches

\begin{tabular}{|c|c|c|c|c|c|}
\hline $\begin{array}{l}\text { Approach } \\
\text { Material } \\
\text { model }\end{array}$ & $\begin{array}{l}\text { (A) } \\
\text { "Rock } \\
\text { mass } \\
\text { strength" }\end{array}$ & $\begin{array}{l}\text { (B) } \\
\text { "Intact } \\
\text { rock } \\
\text { strength" }\end{array}$ & $\begin{array}{l}(\mathrm{C}) \\
" m=0 "\end{array}$ & $\begin{array}{l}\text { (D) } \\
\text { "Cohesion and friction } \\
\text { softening" }\end{array}$ & $\begin{array}{l}\text { (E) } \\
\text { "Cohesion } \\
\text { softening" }\end{array}$ \\
\hline Elastic & $\begin{array}{l}\text { a) } \mathrm{M}-\mathrm{C}^{*} \\
\text { b) } \mathrm{H}-\mathrm{B}^{* *}\end{array}$ & $\begin{array}{l}\text { a) } \mathrm{M}-\mathrm{C} \\
\text { b) } \mathrm{H}-\mathrm{B}\end{array}$ & $\begin{array}{l}\mathrm{H}-\mathrm{B} \text { where } \\
M=0 \text { and } \\
s=0.112\end{array}$ & - & - \\
\hline $\begin{array}{l}\text { Elastic- } \\
\text { perfectly } \\
\text { plastic }\end{array}$ & $\begin{array}{l}\text { a) } \mathrm{M}-\mathrm{C} \\
\text { b) H-B }\end{array}$ & $\begin{array}{l}\text { a) } \mathrm{M}-\mathrm{C} \\
\text { b) H-B }\end{array}$ & - & - & - \\
\hline $\begin{array}{l}\text { Elastic- } \\
\text { brittle } \\
\text { plastic }\end{array}$ & - & - & $\begin{array}{l}\text { H-B } \\
\text { Res. values : } \\
m=0 \text { and } \\
s=0.112\end{array}$ & $\begin{array}{l}\text { M-C; Res. values: } \\
c_{\text {res }}=0.2 \cdot c_{\text {peak }} \\
\emptyset_{\text {res }} \text { is basic frict. angle }\end{array}$ & $\begin{array}{l}\text { M-C; Res. values: } \\
c_{\text {res }}=0.3 \cdot c_{\text {peak }} \\
\emptyset_{\text {res }}=\emptyset_{\text {peak }}\end{array}$ \\
\hline
\end{tabular}

* $\mathrm{M}-\mathrm{C}=$ Mohr-Coulomb criterion

** $\mathrm{H}-\mathrm{B}=$ Hoek-Brown criterion

\subsubsection{Approach (A)}

The strength parameters of the rock mass, when using approach (A) in Table 1, are estimated based on characterisation by using GSI. The peak strength parameters of the rock mass are based on the generalised Hoek-Brown (Hoek et al., 2002) criterion and equivalent Mohr-Coulomb parameters. Both elastic and elastic-perfectly plastic material types are applied.

\subsubsection{Approach (B)}

In approach (B) the intact rock properties were used (e.g. $G S I=100, m_{b}=m_{i}, s=1, a=0.5$ ) and adopted in Mohr-Coulomb and Hoek-Brown criteria to determine the strength parameters. The peak strength parameters of the intact rock are also, similar to approach (A), based on the generalised Hoek-Brown (Hoek et al., 2002) criterion together and equivalent Mohr-Coulomb parameters. Both elastic and elastic-perfectly plastic material types are applied.

\subsubsection{Approach (C)}

In approach (C) an elastic model with $\mathrm{m}=0$ and $\mathrm{s}=0.112$ (Martin, 1997) was adopted in addition to an elastic-brittle-plastic where the residual value were set as $\mathrm{m}=0$ and $\mathrm{s}=0.112$. In the plastic model, the peak strength value was estimated based on classification by using GSI and by adopting Hoek-Brown criterion, as in approach (A).

\subsubsection{Approach (D)}

Approach (D) was based on the suggestion by Hoek et al. (1995) that a rapid loss in cohesion of the rock mass to about $20 \%$ of the peak value and a reduction in friction to the rock basic friction angle could be used as residual values in a plastic analysis. The peak strength value was estimated using GSI and by adopting the equivalent parameters using Mohr-Coulomb criterion, as in approach (A).

\subsubsection{Approach (E)}

Strain dependent models, for instance the cohesion weakening and friction strengthening model (Hajiabdolmajid et al., 2002), require non-simultaneous changes of the friction and cohesion and cannot be studied by the use of simple stress analysis programs utilised in this study. As the recommended residual values defined by Hajiabdolmajid et al. (2002), are difficult to determine an instantaneous softening 
approach (E) was used based on a reduction in cohesion $\left(c_{r e s}=0.3 \cdot c_{\text {peak }}\right.$ and $\left.\varnothing_{\text {res }}=\varnothing_{\text {peak }}\right)$. The peak strength value was estimated using GSI and by adopting the equivalent parameters using Mohr-Coulomb criterion, as in approach (A).

\section{$4 \quad$ Application to case studies}

Five cases with observed fallouts are presented; each resulting from compressive stress induced spalling. All cases have typical tunnel dimensions (approximately 2-10 m), for which the rock mass can be treated as a continuum at depths of 630 to $965 \mathrm{~m}$ below ground surface. All are situated in hard rock masses, with high uniaxial compressive strengths of the intact rock (above $70 \mathrm{MPa}$ ). All cases are also undisturbed by adjacent drifting or mining. Two of the cases, Kobbskaret and Heggura, are road tunnels in Norway, two are vertical raises in the Garpenberg mine, and one is an exploration drift in the Zinkgruvan mine (both mines located in Sweden). Detailed description of the fallouts, together with geological- and measured stress data are presented for each case. Of the five cases, the author has visited the sites of the two raises in Garpenberg and the Kobbskaret tunnel to get more information and better knowledge of how the failure occurred. Information is also based on discussion and communication with the mining/tunnel or underground facility staff. The exploration drift in the Zinkgruvan mine and the Heggura tunnel cases are based solely on documented information. Table 2 presents the derived and used input parameters for each case. In each case, the rock mass has been approximated as an isotropic and continuous material and the stress conditions represented by plane strain conditions. In the Zinkgruvan, Kobbskaret and Heggura cases, the in situ stresses are not perfectly parallel to the $\mathrm{x}, \mathrm{y}$ and $\mathrm{z}$ co-ordinate direction axes of the tunnel. Therefore all stresses have been rotated into the tunnel axis co-ordinate system. The out-of-plane shear strains were thus neglected. More detailed information of all of these cases can be found in Edelbro (2006).

Table 2 Input data for each case used in the numerical modelling

\begin{tabular}{lccccc}
\hline Input data & Garpenberg (1) & Garpenberg (2) & Zinkgruvan & Kobbskaret & Heggura \\
\hline Stress data, & & & & & \\
$\quad \sigma_{\mathrm{H}}(\mathrm{MPa})$ & 45 & 34 & 54.5 & $24.1\left(^{*}\right)$ & $24.6(*)$ \\
$\sigma_{\mathrm{h}}(\mathrm{MPa})$ & 20 & 16 & 54.5 & 17.1 & 8.5 \\
$\sigma_{\mathrm{v}}(\mathrm{MPa})$ & 24 & 19 & 28 & 12.0 & 7.6 \\
$G S I$ & 80 & 80 & 70 & 70 & 80 \\
$\sigma_{\mathrm{ci}}(\mathrm{MPa})$ & 73 & 73 & 300 & 109.5 & 210 \\
Youngs Modulus, $E(\mathrm{GPa})$ & 55 & 55 & 71 & 19 & 43 \\
Poisson's ratio, $v$ & 0.17 & 0.17 & 0.33 & 0.12 & 0.28 \\
$\sigma_{3 \text { max }}(\mathrm{MPa})$ & 23 & 20 & 10 & 12 & 10 \\
Material constant, $m_{i}$ & 15 & 15 & 20 & 28 & 30 \\
\hline * $\sigma_{\mathrm{H}}, \sigma_{\mathrm{h}}$ and $\sigma_{\mathrm{v}}$ represents the transformed principal stresses in the tunnel axis co-ordinate system.
\end{tabular}

\subsection{The Garpenberg raise (1)}

In the Garpenberg mine, owned by Boliden Mineral AB, ore is extracted containing zinc, silver, lead, copper and gold. The unsupported vertical raise has a diameter of $2.13 \mathrm{~m}$, is situated at a depth of 830 to $880 \mathrm{~m}$ below surface and is not influenced by local mining. The raise has been developed in limestone and is directly above an area where stress measurements have been performed by using 3D overcoring (Nilssen, 2004). The initial spalling on the surface of the raise started immediately after raising in the direction perpendicular to the maximum measured stress which confirms the major principal stress direction. The fallouts were small with a maximum depth of $50 \mathrm{~mm}$, see Figure 3.

Based on the results from the numerical analysis, the best agreement with the actual depth of the fallout was observed when using the intact rock approach (B). A depth of 40 to $70 \mathrm{~mm}$ was noted from the intact rock analysis, which is comparable with the observed depth of $50 \mathrm{~mm}$ (Figure 3). However the shape and extent 
of the yielded region did not agree with the observed fallout. The $m=0$ approach (C) using the elastic model resulted in a large overestimation of the size of the fallout. None of the results from the elastic-brittle plastic models $(\mathrm{C}, \mathrm{D}$ and $\mathrm{E})$ did correspond with the actual failure, as the predicted region of fallout was overestimated in extent and by a factor of 7.5 to 14 in depth (Figure 4).

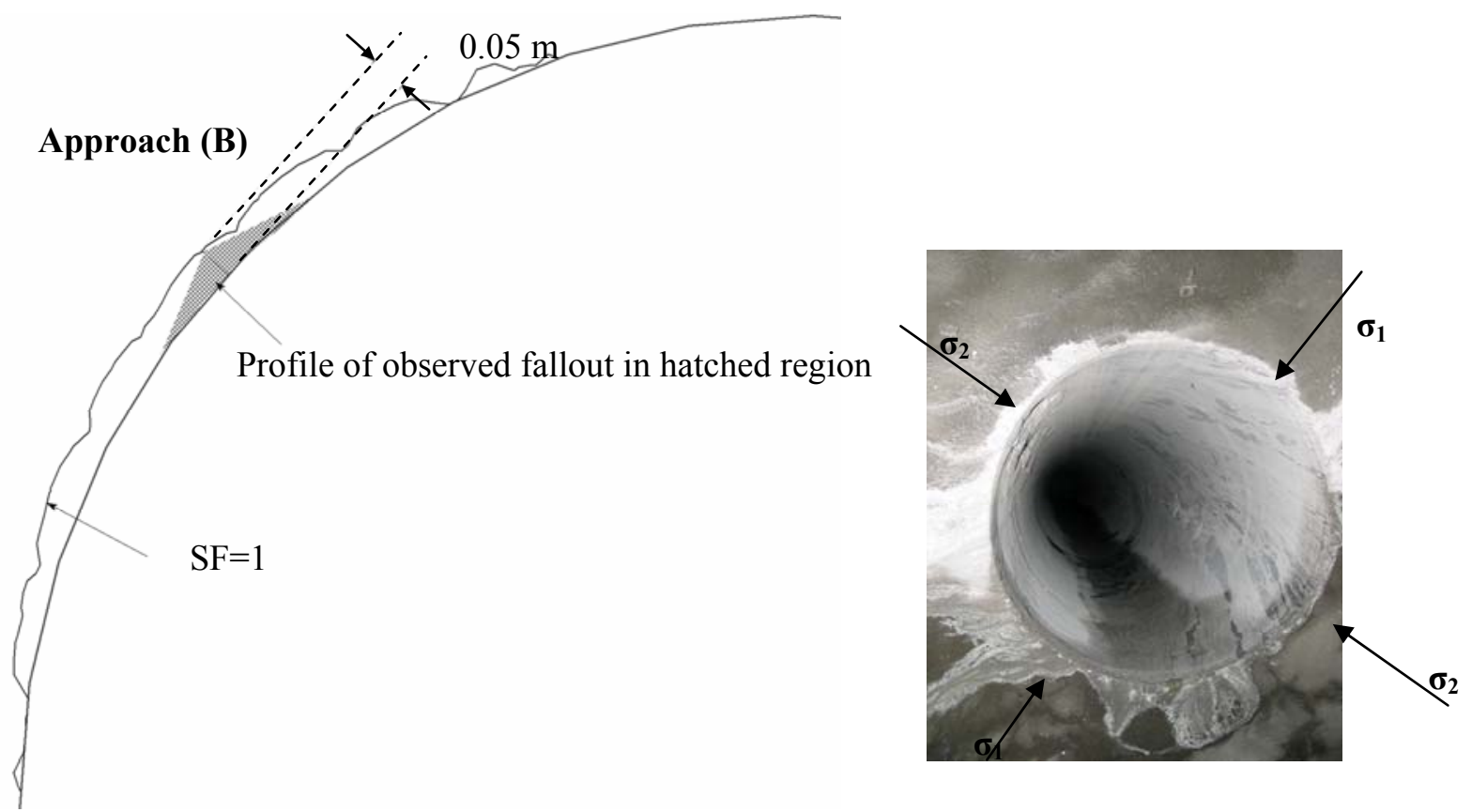

Figure 3 The fallout area for the Garpenberg raise (1) predicted using an elastic analysis and HoekBrown strength parameters for the intact rock (approach (B)) in Phase $^{2 D}$ together with a photo of the raise at level $880 \mathrm{~m}$ (Photo courtesy of Boliden Mineral AB)

Approach (E)

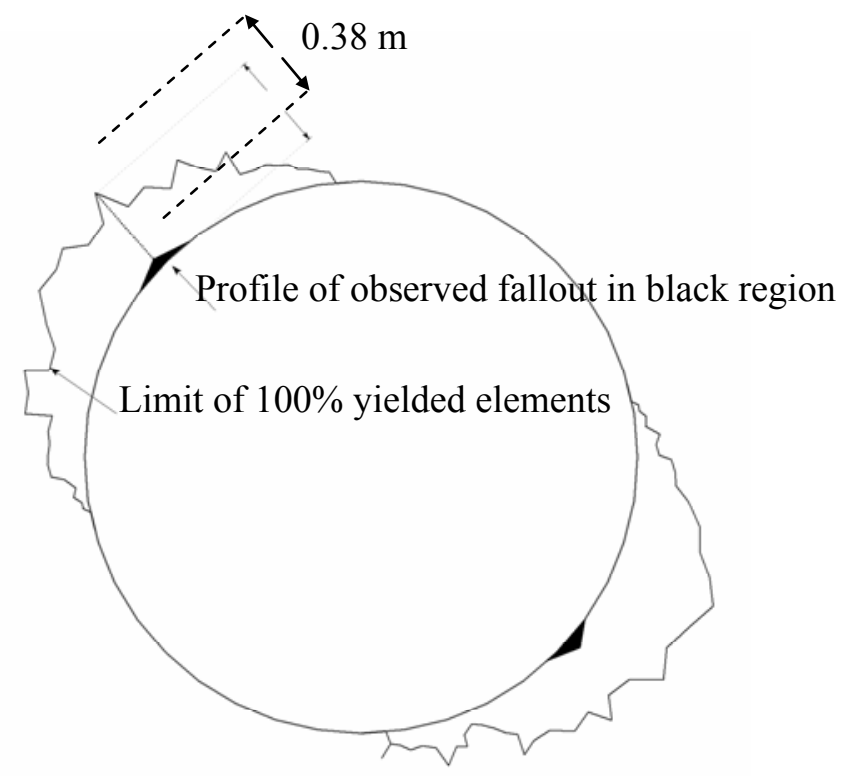

Figure 4 The fallout area for the Garpenberg raise (1) predicted using an elastic-brittle plastic analysis and Mohr-Coulomb criterion with cohesion weakening residual parameters (approach (E)) in Phase ${ }^{2 D}$ 


\subsection{The Garpenberg raise (2)}

This vertical raise, with a diameter of $4.5 \mathrm{~m}$, is situated in limestone at a maximum depth of $700 \mathrm{~m}$ below surface and is not influenced by local mining. The same stress measurement results performed at level $880 \mathrm{~m}$ for the Garpenberg raise (1), (see Section 4.1) are applied to this case, with adjustments for approximately $200 \mathrm{~m}$ elevation difference. The actual fallouts are more or less perpendicular to the measured major principal stress at level 880, which makes the stress data also relevant for this case. The fallouts of the intact rock mass had a typical depth of $100 \mathrm{~mm}$.

The same result as for the Garpenberg raise (1) could be seen for the Garpenberg raise (2), except that the depth and extent of the area of the zone with $\mathrm{SF}<1$ and yielded elements of $100 \%$ always was greater when analysing the Garpenberg raise (2). The best correspondence with the actual depth of the fallout was observed when using the intact rock approach (B).

\subsection{The exploration drift in Zinkgruvan mine}

The Zinkgruvan mine, owned by Lundin Mining, is located in the south-central part of Sweden. Spalling failure was observed in an exploration drift, as shown in Figure 5. The failure surfaces were fresh, indicating intact rock mass failure, not influenced by geological structures. The fallout depth was limited to 0.1 to $0.2 \mathrm{~m}$ in the roof of the drive. The exploration drift is undisturbed by adjacent mining and the dominating rock type is a brittle, quartz-feldspar leptite. Failure was not observed when the drift was parallel to the major horizontal stress and began to occur when the drive changed direction, to being oblique to the maximum stress (Figure 5). Stress measurements have been performed by 3D overcoring in the nearby area at $960 \mathrm{~m}$ depth. As for all other cases, a plane strain condition was assumed, with stresses transformed to the twodimensional analyses plane (perpendicular to the drift). However, in this particular case it would be more correct to assume complete plane strain condition or a 3D simulation, to be able to consider the true stresses. This was however outside the scope of the present work.

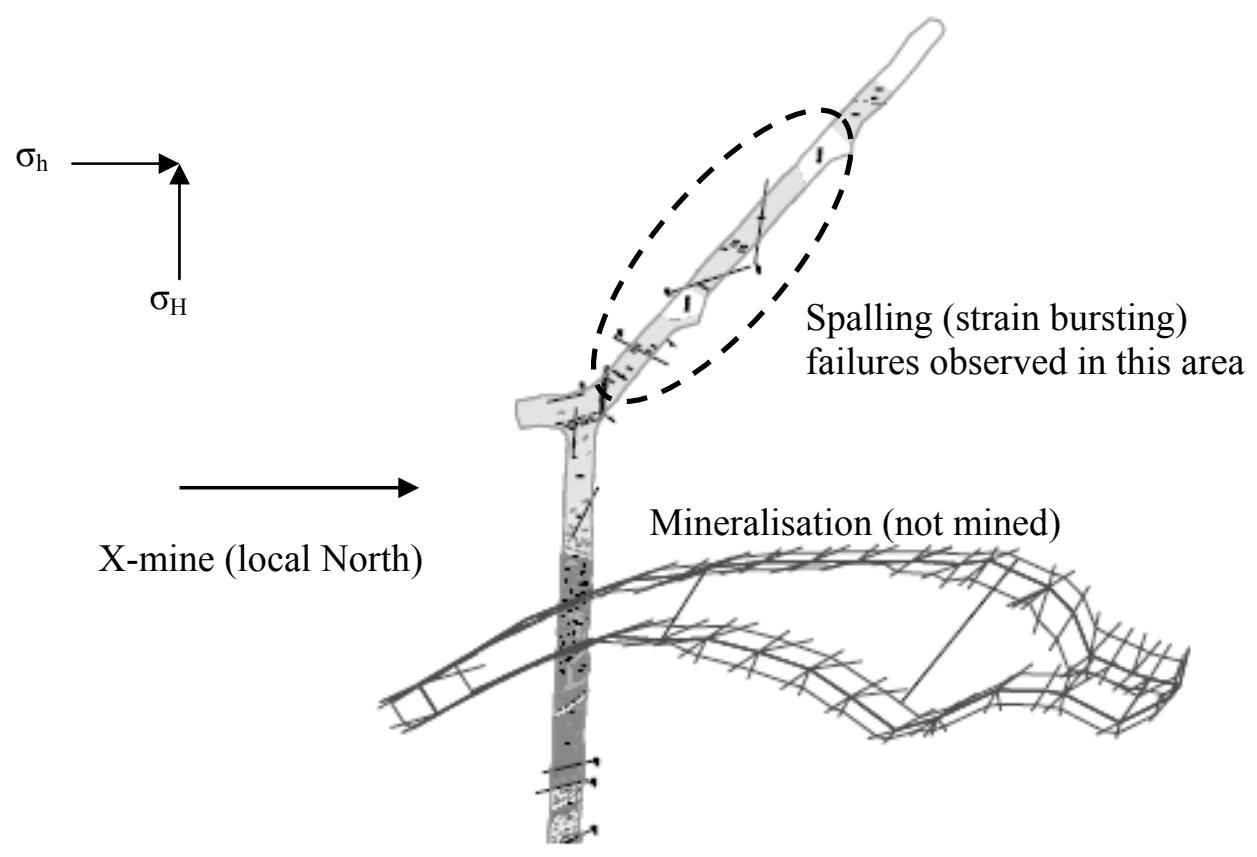

Figure 5 Horizontal view showing the exploration drift at the $965 \mathrm{~m}$ level, with mapped geology and the copper orebody shown in red, and area of observed spalling failure marked (from Sjöberg, 2005)

The results from the intact rock approach (B) indicated no fallout. The best agreement with the actual depth of the fallout was observed when using the rock mass strength parameters defined by the GSI system and the Mohr-Coulomb criterion, approach (A), and the plastic model using the $m=0$ approach (C), as shown in 
Figure $6 \mathrm{a}$ and $6 \mathrm{~b}$. The results when using these approaches (A and C) showed an underestimation of the depth of the fallout while the results from the approaches $\mathrm{D}$ and $\mathrm{E}$ showed large overestimation of the depth and extent (Figure 6c). The result from the elastic analysis with an $m=0$ approach (C) did not indicate a fallout of the middle of the roof, instead the upper left and right corner of the roof had a $S F<1$.

a)

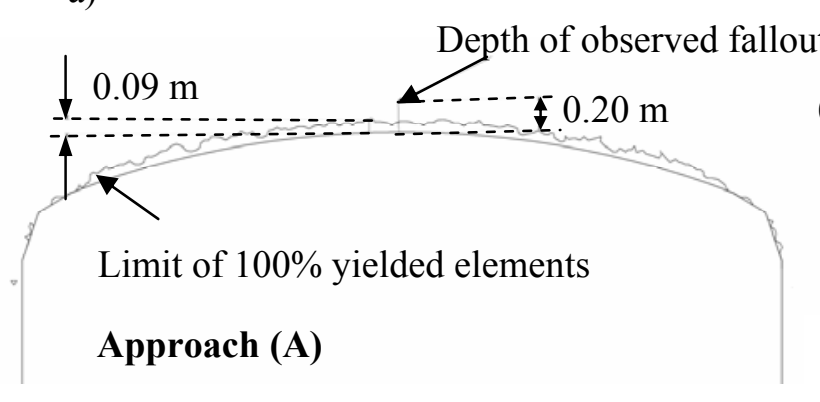

b)

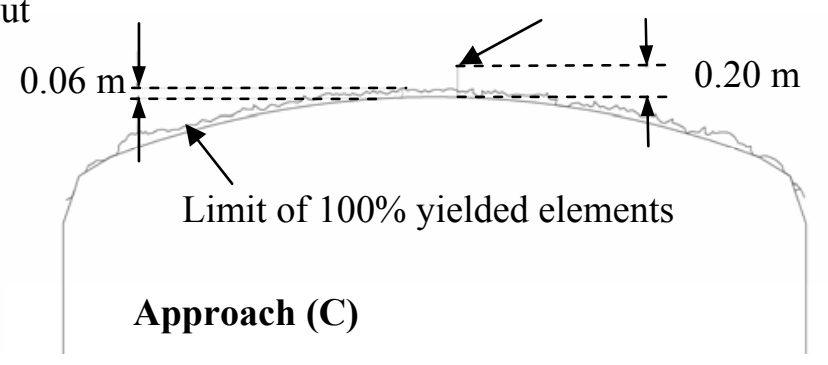

c)

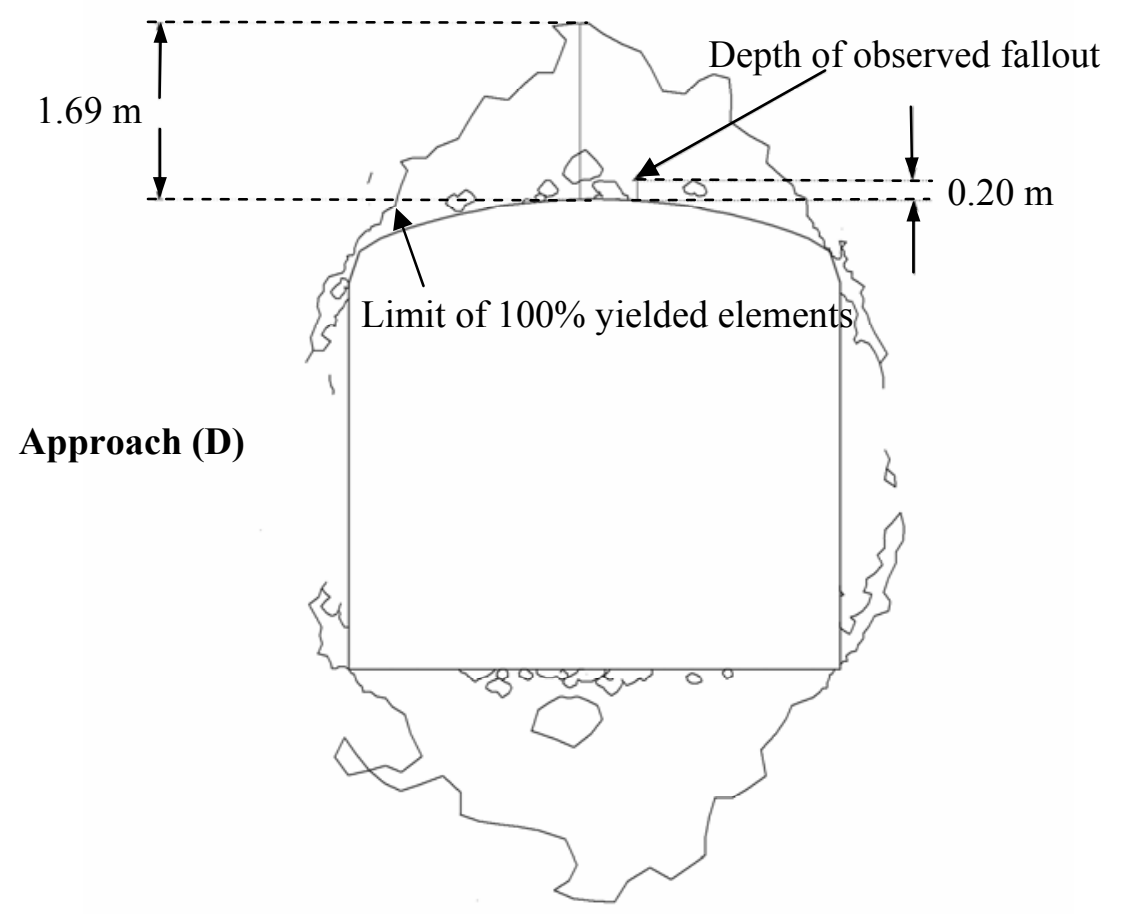

Figure 6 The predicted fallout area for the exploration drift in the Zinkgruvan mine when using a plastic analysis and: a) approach (A), b) approach (C) and c) approach (D) in Phase2D

\subsection{The Kobbskaret tunnel}

The Kobbskaret road tunnel, situated in northern Norway, was officially opened in 1986 . The $4457 \mathrm{~m}$ long tunnel has a typical tunnel area of about 45 to $50 \mathrm{~m}^{2}$ and was excavated by conventional drill and blast tunnelling from both ends. The region is characterised by extensive foliation, spalling and buckling of slabs at the rock ground surface, indicating high, horizontal tectonic stresses. Along the entire tunnel length, the rock mass is composed of Precambrian coarse grained, gneissic granite (Kildemo, 1985). The mountains in the area have heights of about $1000 \mathrm{~m}$ above sea level (Figure 7).

Due to the high rock stresses, heavy spalling occurred in the tunnel roof, both during excavation and after completion of the tunnel. Stress measurements have been performed by $3 \mathrm{D}$ overcoring at $630 \mathrm{~m}$ depth (Kildemo, 1985). Five fallouts have been documented from 1997 to 2004 with a depth of 0.05 to $0.3 \mathrm{~m}$ (Kildemo, 1985; Myrvang et al., 1997). 
Surface/orientation of mountain range

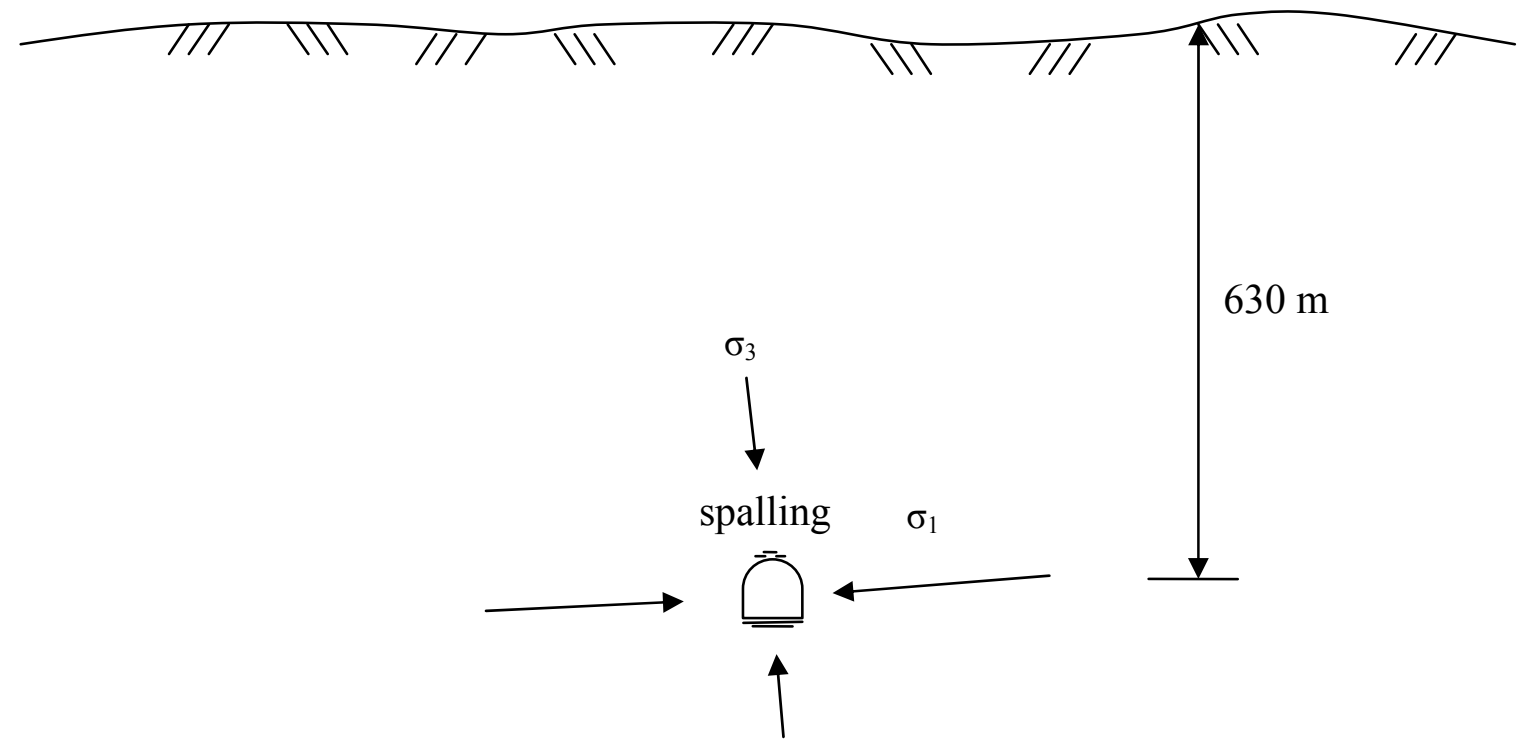

Figure 7 Schematic cross section through analysed portion of the Kobbskaret tunnel (not to scale)

The intact rock approach (B) indicated no fallout. For this case, the best agreement with the actual depth of the fallout was observed when using strength parameters defined by Mohr-Coulomb criterion and the GSI system in approach (A), (see Figure 8a). A depth of 0.15 to $0.3 \mathrm{~m}$ was noted, in the roof of the tunnel, which is comparable to the observed depth. The results from the plastic model when using Mohr-Coulomb criterion in approach (A), did not indicate a large failed zone in the floor as the other plastic models. The second best choice of approach is the " $m=0$ " approach $(\mathrm{C})$, as shown in Figure $8 \mathrm{~b}$, where the fallout depth is predicted as $0.4 \mathrm{~m}$. Also the approach (A), when using strength parameters defined by Hoek-Brown criterion and the GSI system showed reasonable agreement in depth. None of the results from the elastic-brittle plastic models (approaches (D) and (E)) did correspond with the actual fallout, as the determined fallout had a depth of about $4.3 \mathrm{~m}$ when using cohesion and friction weakening in approach (D), (Figure 8c) and a depth of about $1.4 \mathrm{~m}$ when using cohesion weakening in approach (E), Figure 8d.

\subsection{The Heggura tunnel}

The Heggura road tunnel, situated in western Norway, was constructed in 1981-1982 and it was the first tunnel in Norway to use steel fibre reinforced shotcrete. The tunnel is only a few meters above sea level, as shown in Figure 9. The fallouts due to spalling were observed in the upper right corner and partly in the lower left corner as shown in Figure 9 (Myrvang et al., 1997). In the region where the 3D overcoring stress measurements have been performed, the fallouts were limited to just a few centimetres (Sörheim, 1981). Here, the determined rock mass properties from the stress measurement area are used and not the general $/$ mean values for the whole tunnel.

The compressive fallout region was only predicted to occur in the upper right corner of the roof when using the elastic model in approach (A) with strength parameters determined by Mohr-Coulomb criterion and the brittle-plastic model in approach (D). Most of the used approaches (except approach (B) and approach (C) when using the elastic model) indicated tensile failure in the upper left corner and in the lower right wall/floor. This was not observed in field and a full analysis is outside the scope of this paper. The compressive fallout in the lower left corner was observed in the results from all approaches. Still it is important to note that this is the only case where the location of the actual fallout could not be predicted by all of the used approaches. 

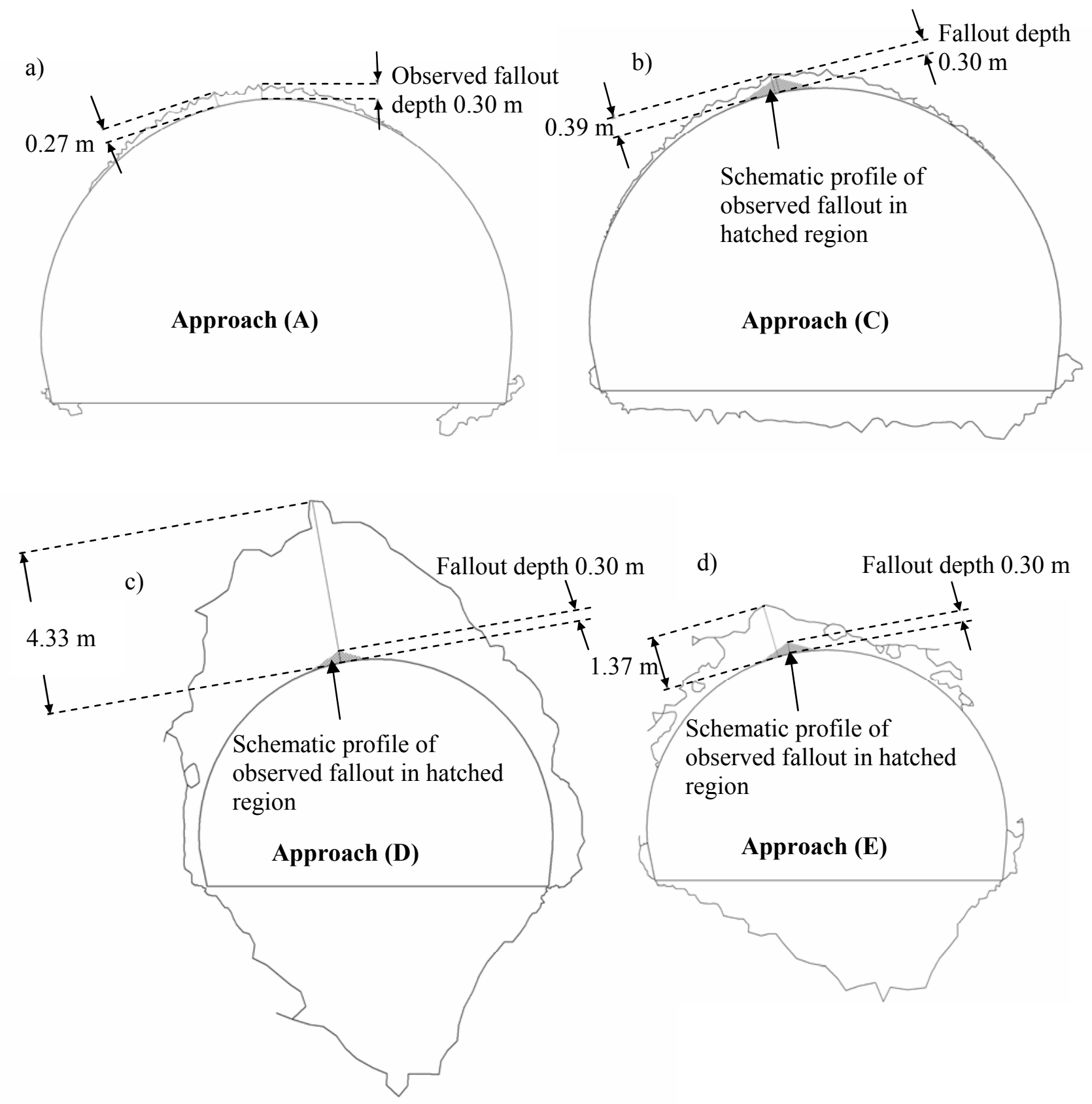

Figure 8 The predicted fallout area, represented by a $100 \%$ yielded element zone, for the Kobbskaret tunnel using an plastic analysis and a) approach (A), b) approach (C), c) approach (D) and d) approach (E) in Phase $^{2 D}$ 


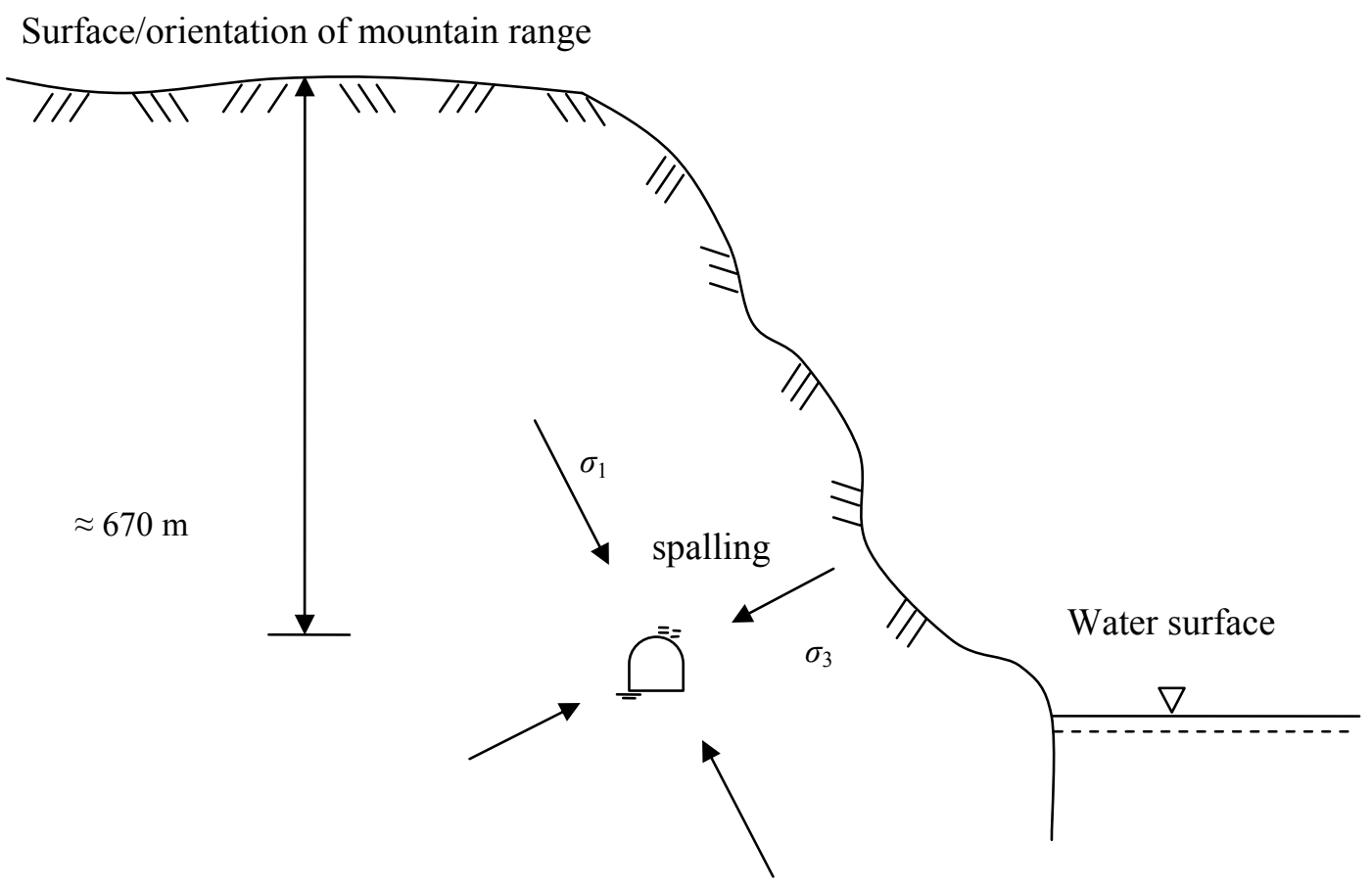

Figure 9 Schematic cross section through the Heggura tunnel (not to scale)

\section{Discussion}

To calibrate field data with results from numerical analysis is waste of time if the basic numerical model does not resemble the reality. The present study is an evaluation of existing widely known and familiar approaches to simulate and estimate possible brittle fallouts by simple stress analysis programs. As the aim is to find the best non-calibrated approach, only raw data have been used by the author, without modifications. In general, approach (A), where the rock mass strength parameters are defined by the GSI system, showed the best agreement with observed fallouts. However the extent of the fallout zone was overestimated for all cases and the shape was predicted to be arched-formed as opposed to the true v-notch shape. The arch form is mainly due to the used stress analysis programs which imply that a failure occur when the stress in the material exceeds the material strength. The contours of the principal stresses are often arched-formed around the boundary which also results in strength factors and yielded elements that are arched formed.

The results from approach (B), where the intact rock strength parameters were used, showed a very good correlation with actual fallout depth when applied in the Garpenberg raise cases. In all other cases, no fallouts were predicted. This is due to the Garpenberg raises having a measured major principal stress that is greater than the determined global and uniaxial compressive strength of the rock mass, when using RocLab (Rocscience, 2006). In all other cases, the intact rock is too strong compared to the prevailing stresses for fallout to occur. The depth of the predicted fallout is deeper when using approach (A) compared to approach (B) but they both show an exaggeration of the extent of the fallout.

The brittle plastic models with instantaneous softening of cohesion and friction, approach (D), or cohesion weakening, approach (E), did not agree with the actual fallout as the results showed a large overestimation of the fallout zone. This is opposite to that reported by Martin (1997), as the use of approach (D) for the URL case underestimated the fallout depth.

Since the tensile strength cannot be accounted for and as the post yield response cannot be simulated correctly, the $m=0$ approach is inappropriate for inelastic modelling (Diederichs et al., 2007). In this study, the $m=0$ approach (C), for the plastic analysis has resulted in better agreement with actual fallout compared to the elastic analysis. The elastic model when using the $m=0$ approach (C) differs significantly from the real fallout and often the depth and extent of the fallout is overestimated with an incorrect shape. 
For those approaches where the elastic model can be compared with an elastic-plastic model, the elasticperfectly plastic model results in a slightly deeper fallout zone (except for the Heggura case) when using approach (A). This was also shown by Hajiabdolmajid et al. (2002). When using the intact rock strength by approach (B) the result was the opposite.

When comparing the elastic analysis by using both Examine ${ }^{2 \mathrm{D}}$ and $\mathrm{Phase}^{2 \mathrm{D}}$ the result is the same, except that in Examine ${ }^{2 \mathrm{D}}$ an exact $m=0$ approach can not be simulated as $m_{b}$ must be greater than 0.001 , which however is insignificant for the results.

Based on this study, none of the used approaches gave perfect agreement with the actual fallouts, although this was not expected from this study, as the aim was to find the best non-calibrated approach. Within each approach, failure strength criteria and material models are incorporated. Concerning the criteria, there were slight differences in result when the strength parameters were defined by the Hoek-Brown criterion compared to the Mohr-Coulomb criterion. Therefore, none of these criteria can be selected as preferable (or unfavourable) in this study. As mentioned, the approach (E) concerning a strain dependent cohesion weakening and friction strengthening model, resulted in good agreement with the fallout at the URL case (Hajiabdolmajid et al., 2002). The used material models in these 2D stress analysis programs may result in poor reproductions of brittle fallouts and other material models may be better suited for these conditions.

Another way of simulating the failure process is by successive removal of failed elements. This was mainly performed for the URL case when the elastic and elastic-brittle plastic models did result in an under prediction of the fallout depth. The depth of the failed zone was overestimated by a factor of 2 to 3 when using this kind of method (e.g Martin, 1997). Therefore this application has not been used in this paper, as approach (A) already over predicts the depth. However the approach (B), using the intact rock strength, showed an underestimation of the fallout and would perhaps be better suited for such simulation.

The input data used in this paper are summarised from field studies, reports and papers. It is possible that some important information has been left out and also that the used input data do not respond the actual rock mass behaviour and fallout mechanisms. The rock mass are characterised by the GSI system, that are basic and easy to use but is perceived as inaccurate by the author. Also the measured stresses for each case could be more correct used by a complete plane strain approach.

As mentioned earlier, it was assumed that an area of $100 \%$ yielded elements or SF less than one represents fallout but may represent damaged rock, as in Figure 1. The question is then how to simulate a fallout zone and how can the damaged rock beyond that zone be simulated. Despite the fact that none of the approaches in this study showed perfect agreement with the actual fallouts, a 2D stress analysis program can be used for guidance of where, on the boundary, the actual compressive fallout will occur. Also when using the approach (A), SF $<1$ and $100 \%$ yielded elements can be used to predict a reasonable depth of the fallout. However it is important not just to focus on the strength factor or the yielded elements as indicators for the compressive fallout, as for example, negative values of sigma 3 show areas in tension, the volumetric and maximum shear strain show areas where the rock has deformed etc. These indicators for fallouts often result in other shapes of the contours of the fallout. It is recommended that further work in this area is focused on trying to achieve more precise approaches, for reproduction of the different failure processes.

\section{Conclusion}

A perfect agreement of the used approaches with the observed fallouts was not observed and neither expected from this study, as the aim was to find the best non-calibrated approach. However, this study identified that approach (A) yielded the most reasonable estimate of fallout depth and is thus considered the best non-calibrated model. Still a precise estimation can not be expected.

There were slight differences in results when the strength parameters were defined by the Hoek-Brown criterion compared to the Mohr-Coulomb criterion. Therefore, neither of these criteria can be selected as preferable (or unfavourable) to use when predicting a fallout.

The identified possible sources of errors, why the used approaches do not reproduce the observed fallout, is mainly due to incorrect (i) approaches, (ii) material models, (iii) failure criteria, (iv) input data in the form of e.g. stress conditions and characterisation system are used. 


\section{Acknowledgements}

The authors acknowledge the financial support by LKAB, the Research Council of Norrbotten, the LKAB Foundation, the consortium "Väg Bro Tunnel" (Road Bridge Tunnel), Trelleborgsstiftelen, and the Luleå University of Technology. Special thanks go to my supervisor, Adjunct Professor Jonny Sjöberg, at Vattenfall Power Consultant, for invaluable discussions, suggestions and advice.

\section{References}

Diederichs, M. (1999) Instability of hard rock masses: the role of tensile damage and relaxation. PhD thesis, Department of Civil Engineering, University of Waterloo, Waterloo, Canada, 566 p.

Diederichs, M., Kaiser, P.K. and Eberhardt, E. (2004) Damage initiation and propagation in hard rock tunnelling and the influence of near-face stress rotation, Int. J. Rock Mech. Min. Sci, 41, pp. 785-812.

Diederichs, M.S., Carvalho, J.L. and Carter, T.G. (2007) A modified approach for prediction of strength and post yield behaviour for high GSI rock masses in strong, brittle ground. Proceedings 1st Canada-US Rock Mechanic symposium, Vancouver, Canada, 27-31 May, ISBN 978-0-415-44401-9.

Edelbro, C. (2006) Strength of hard rock masses: a case study, Technical report, Division of Mining and Geotechnical Engineering, Luleå University of Technology, available online: epubl.luth.se/1402-1536/2006/13.

Hajiabdolmajid, V., Kaiser, P.K. and Martin, C.D. (2002) Modelling brittle failure of rock, Int. J. Rock Mech. Min. Sci, Vol. 39, pp. 731-741.

Hoek, E., Kaiser, P.K. and Bawden, W.F. (1995) Support of underground excavations in hard rock, A.A. Balkema/Rotterdam/Brookfield.

Hoek, E. and Karzulovic, A. (2001) Rock mass properties for surface mines, Slope stability in surface mining, Hustrulid, Carter, Van Zyl (eds), Society for Mining, Metallurgy, and Exploration Inc. (SME), Chapter 6.

Hoek, E., Carranza-Torres, C. and Corkum, B. (2002) Hoek-Brown failure criterion -2002 edition. Proceedings $5^{\text {th }}$ North American Rock Mechanics Symposium and $17^{\text {th }}$ Tunnelling Association of Canada Conference: NARMSTAC 2002, July 7-10, University of Toronto, pp. 267-271.

Kildemo, G.A. (1985) En bergmekanisk undersökelse av Kobbskaret Vegtunnel (in English: A rock mechanics investigation in the Kobbskaret tunnel). MSc thesis, Norwegian Institute of Technology, Trondheim (in Norwegian).

Marinos, V., Marinos, P. and Hoek, E. (2005) The geological strength index: applications and limitations, Bull Eng Geol Environ, 64, pp. 55-65.

Martin, C.D. (1997) $17^{\text {th }}$ Canadian Geotechnical Colloquium: The effect of cohesion loss and stress path on brittle rock strength, Can. Geotech. J. 34, pp. 698-725.

Martin, C.D., Read, R.S. and Martino, J.B. (1997) Observations of brittle failure around a circular test tunnel, Int. J. Rock Mech. Min. Sci, Vol. 34 (7), pp. 1065-1073.

Martin, C.D. (1998) Estimating ground support for underground openings in hard rock, Bergmekanikdagen, SveBeFo, Stockholm.

Martin, C.D., Kaiser, P.K. and McCreath, D.R. (1999) Hoek-Brown parameters for predicting the depth of brittle failure around tunnels. Canada Geotech. J. Vol. 36 (1), pp. 136-151.

Myrvang, A.M. (1991) Estimation of in situ compressive strength of rocks from in situ stress measurements in highly stressed rock structures. Proceedings $7^{\text {th }}$ ISRM Congress on Rock Mechanics, Aachen, W. Wittke (editor), A.A. Balkema, Rotterdam, pp. 573-575.

Myrvang, A.M., Alnaes, L., Hansen, S.E. and Davik, K.I. (1997) Heavy spalling problems in road tunnels in Norway Long time stability and performance of sprayed concrete as rock support. International symposium on rock support: applied solutions for underground structures, Lillehammer, 22-25 June 1997, Norwegian Society of Chartered Engineers, Oslo, ISBN 82-91341-18-4.

Nilssen, P. (2004) Bergspenningsmålinger i Garpenberg Norra gruve, SINTEF bygg og miljø - Berg og geoteknikk. STF22 F04110.

Rocscience Inc. (2005) Phase Version 6.020 - Finite Element Analysis for Excavations and Slopes. www.rocscience.com, Toronto, Ontario, Canada.

Rocscience Inc. (2006) RocLab Version 1.021 - Rock mass strength analysis using the Hoek-Brown failure criterion. www.rocscience.com, Toronto, Ontario, Canada.

Rocscience Inc. (2007) Examine Version 7.004 - 2D Stress Analysis for Underground Excavations. www.rocscience.com, Toronto, Ontario, Canada.

Sjöberg, J. (2005) Rock mechanics analysis of the copper orebody, SwedPower Report 2050700-01 (confidential).

Sörheim, S. (1981) Bergtrykksvariasjoner og sikring i Heggura vegtunnel (in English: Rock stress changes and support in the Heggura tunnel), M.Sc. thesis, Norwegian Institute of Technology, Trondheim (in Norwegian). 